\title{
The Medial Preoptic Nucleus Integrates the Central Influences of Testosterone on the Paraventricular Nucleus of the Hypothalamus and Its Extended Circuitries
}

\author{
Martin Williamson, Brenda Bingham, Megan Gray, Leyla Innala, and Victor Viau \\ Neuroscience Program, Department of Cellular and Physiological Sciences, University of British Columbia, Vancouver, British Columbia, Canada V6T 1Z3
}

Testosterone contributes to sex differences in hypothalamic-pituitary-adrenal (HPA) function in humans and rodents, but the central organization of this regulation remains unclear. The medial preoptic nucleus (MPN) stands out as an important candidate in this regard because it contains androgen receptors and projects to forebrain nuclei integrating cognitive-affective information and regulating HPA responses to homeostatic threat. These include the HPA effector neurons of the paraventricular nucleus (PVN) of the hypothalamus, medial amygdala, and lateral septum. To test the extent to which androgen receptors in the MPN engage these cell groups, we compared in adult male rats the effects of unilateral microimplants of testosterone and the androgen receptor antagonist hydroxyflutamide into the MPN on acute restraint induced activation and/or neuropeptide expression levels. The basic effects of these implants were lateralized to the sides of the nuclei ipsilateral to the implants. Testosterone, but not hydroxyflutamide implants, decreased stress-induced Fos and arginine vasopressin (AVP) heteronuclear RNA expression in the PVN, as well as Fos expression in the lateral septum. In unstressed animals, AVP mRNA expression in the PVN decreased and increased in response to testosterone and hydroxflutamide MPN implants, respectively. The differential influences of these implants on AVP mRNA expression were opposite in the medial amygdala. These results confirm a role for androgen receptors in the MPN to concurrently modulate neuropeptide expression and activational responses in the PVN and its extended circuitries. This suggests that the MPN is capable of bridging converging limbic influences to the HPA axis with changes in gonadal status.

\section{Introduction}

Stress or threats to homeostasis activate the hypothalamic-pituitary-adrenal (HPA) axis by initiating the recruitment of neurosecretory neurons in the paraventricular nucleus (PVN) of the hypothalamus to secrete peptide stores from the median eminence, primarily corticotropin-releasing hormone $(\mathrm{CRH})$ and arginine vasopressin (AVP). Together, these synergize on the release of adrenocorticotropin hormone from the anterior pituitary to regulate glucocorticoid release from the adrenal gland (Aguilera, 1994).

In humans and rodents, the stress-induced secretion of glucocorticoids is lower in males than in females, and this sex difference may be explained by inhibitory actions of testosterone on the HPA axis (Kudielka and Kirschbaum, 2005). Several types of physiological and affective disorders in human males are associated with a decrease in testosterone and an increase in glucocorticoid secretion, and both of these hormonal responses may be maladaptive (Williamson et al., 2005; Uhart et al., 2006). Determining the organization of androgen-sensitive projections to the

Received June 4, 2010; revised July 9, 2010; accepted July 12, 2010.

This study was supported by the Canadian Institutes of Health Research (V.V.)

Correspondence should be addressed to Victor Viau, Department of Cellular and Physiological Sciences, Life Sciences Centre, The University of British Columbia, 2350 Health Sciences Mall, Vancouver, BC, Canada, V6T 173. E-mail:viau@interchange.ubc.ca.

DOI:10.1523/JNEUROSCI.2852-10.2010

Copyright $\odot 2010$ the authors $\quad$ 0270-6474/10/3011762-09\$15.00/0
HPA axis, therefore, is critical for understanding individual differences in susceptibility to stress-related disease.

Beyond representing an important nodal point for mediating sensory and sex steroid influences on reproductive behavior, emerging evidence underscores a role for the medial preoptic nucleus (MPN) to regulate the HPA axis. This may be mediated by a direct influence of androgen-sensitive projections, because the MPN contains the highest number of androgen receptor (AR)-positive cells in the forebrain identified as projecting to the PVN region (Williamson and Viau, 2007). However, on the basis of previous functional studies by Lund et al. (2006) and our own retrograde experiments, testosterone is capable of regulating the HPA axis in the vicinity of the PVN region and within several brain nuclei identified as expressing androgen receptors and projecting to the PVN.

The MPN also extensively projects to regions of the forebrain and brainstem that regulate a variety of behaviors and physiological mechanisms related to homeostasis (Simerly and Swanson, 1988). The septum and medial amygdala stand out as important relays in this regard, because both of these regions regulate HPA activity and receive substantial input from the MPN (Risold and Swanson, 1997). Moreover, AVP pathways originating from the medial amygdala, including those projecting to the lateral septum, regulate a variety of behaviors associated with autonomic, emotional, and coping responses to stress (Liebsch et al., 1996).

Based on this evidence, we hypothesize that the MPN might be in a position to modify multiple afferent mediators of PVN mo- 
tor function. Thus, in the present study, we sought to determine (1) the extent to which the MPN represents the seat of the central actions of testosterone on the PVN and its extended circuitries, and (2) whether the local actions of testosterone in the MPN actually depend on the androgen receptor. Our strategy incorporated a discrete unilateral steroid/antagonist microimplant approach to avoid other androgen receptor-rich populations in the vicinity and to exploit the unilateral projections of the MPN.

\section{Materials and Methods}

Animals. One hundred nine adult male Sprague Dawley rats (Charles River) were used, weighing $250 \mathrm{~g}$ on arrival ( $56 \mathrm{~d}$ old) and $375 \mathrm{~g}$ when sampled ( $\sim 75 \mathrm{~d}$ old). Animals were pair-housed in a colony room under controlled temperature and lighting conditions (12 h light/dark cycle, lights on at 6:00 A.M.) with food and water available ad libitum. Testing was performed during the light phase of the cycle, beginning at 8:00 A.M.. All experimental protocols were approved by the University of British Columbia Animal Care Committee.

Intracerebral microimplants. Body-weight-matched animals were anesthetized and received stereotaxically guided, unilateral implants of testosterone (Sigma Chemical) or the AR antagonist hydroxyflutamide (Toronto Research Chemicals) using 22 gauge cannula ejectors aimed to terminate $0.5 \mathrm{~mm}$ dorsal to the MPN (based on Lund et al., 2006). Coordinates used for MPN microimplants were $0.29 \mathrm{~mm}$ rostral to bregma, $0.8 \mathrm{~mm}$ lateral to the midline, and $7.0 \mathrm{~mm}$ ventral from the pia. Testosterone and hydroxyflutamide were dissolved in a heated suspension of beeswax (VWR International) to a final concentration of $0.3 \mathrm{M}$ (Christensen and Gorski, 1978; Lund et al., 2006), packed to a height of $\sim 400 \mu \mathrm{m}$, and ejected using a 28 gauge wire that extended $0.5 \mathrm{~mm}$ beyond the tip of the cannula. Experimental control animals received stereotaxically guided, unilateral implants of beeswax alone. To avoid the possibility of functional differences attributed to laterality, half of the animals received implants on either the left or right sides of the MPN.

To determine the extent of diffusion after microimplantation and coordinates for proper placement in the MPN, testosterone and hydroxyflutamide were unilaterally implanted into the MPN using a group of castrated animals. Because AR staining is virtually abolished by the removal of endogenous testosterone, we used the pattern and quality of AR staining induced by these compounds to provide an index of transport and delivery (see Results and Figs. 1,2). To verify that the effects of the implants could not attributed to a potential disruption of MPN integrity, we also compared central measures of HPA function and neuropeptide expression in an additional subset of control animals with testes, including surgical controls (anesthesia only) and those bearing unilateral MPN implants of beeswax (see Results).

Blood sampling and hormone assays. After $14 \mathrm{~d}$ of recovery, during which time animals were handled, blood samples were obtained via the tail vein immediately after removal from the home cage and/or at the termination of a single exposure to stress, which involved placing rats into flat-bottom Plexiglas restrainers $(8.5 \times 21.5 \mathrm{~cm}$; Kent Scientific) for $30 \mathrm{~min}$. Based on our previous time course studies, the $30 \mathrm{~min}$ time point is reliable for simultaneously detecting, within individual animals, changes in HPA activity and intervening levels of Fos activation in the PVN attributable to differences in gonadal status (Viau et al., 2003, 2005). Blood samples were collected into ice-chilled aprotinin-EDTAtreated tubes ( $3.75 \mathrm{mg}$ of EDTA/100 $\mu$ l of blood), centrifuged at $3000 \times$ $g$ for $20 \mathrm{~min}$, and stored at $-20^{\circ} \mathrm{C}$ until assayed.

To survey possible implant effects on testosterone secretion and HPA outflow, plasma testosterone $(25 \mu \mathrm{l})$, corticosterone $(5 \mu \mathrm{l})$, and ACTH $(50 \mu \mathrm{l})$ concentrations were measured using commercial RIA kits (MP Biomedical). For corticosterone, the plasma samples were diluted 1:100 and 1:200 for pre-stress and post-stress time intervals, respectively, to render hormone detection within the linear part of the standard curve. The intraassay and interassay coefficients of variation for all of the assays typically ranged from 3 to $6 \%$ and 10 to $12 \%$, respectively, and ${ }^{125} \mathrm{I}$ labeled ligands were used as tracer in all cases. The standard curve $\mathrm{ED}_{50}$ for the testosterone RIA was $1.2 \mathrm{ng} / \mathrm{ml}$, with a detection limit of 0.1 $\mathrm{ng} / \mathrm{ml}$. The standard curve $\mathrm{ED}_{50}$ for the corticosterone RIA was $17 \mu \mathrm{g} / \mathrm{dl}$, with a detection limit of $0.625 \mu \mathrm{g} / \mathrm{dl}$. The standard curve $\mathrm{ED}_{50}$ for the ACTH RIA was $82 \mathrm{pg} / \mathrm{ml}$, with a detection limit of $20 \mathrm{pg} / \mathrm{ml}$.

Perfusion and tissue processing. Immediately after blood sampling, rats were perfused under deep chloral hydrate anesthesia $(350 \mathrm{mg} / \mathrm{kg}$, i.p.), which was reliably achieved within 1-2 min of drug administration. Rats were sequentially perfused via the ascending aorta with ice-cold $0.9 \%$ saline and then $4 \%$ paraformaldehyde, $\mathrm{pH} 9.5$, at a flow rate of $20 \mathrm{ml} / \mathrm{min}$ and over 5 and $20 \mathrm{~min}$, respectively. Brains were postfixed for $4 \mathrm{~h}$ and stored overnight with $15 \%$ sucrose in $0.1 \mathrm{~m}$ potassium PBS (KPBS), $\mathrm{pH}$ 7.3 , before slicing. Five 1 -in- 5 series of frozen $30-\mu \mathrm{m}$-thick coronal sections through the length of the brain were collected and stored in cryoprotectant (30\% ethylene glycol and 20\% glycerol in sterile DEPC-treated water) at $-20^{\circ} \mathrm{C}$. Adjacent tissue series from each animal were used for separate immunocytochemical and in situ hybridization analyses. In all cases, an additional series was counterstained with thionin and alternately compared with dark-field and bright-field illuminations for morphological and anatomical reference.

Immunohistochemistry. AR immunoreactivity was localized using a primary antiserum $(0.025 \mu \mathrm{g} / \mathrm{ml} ; 1: 8000)$ raised against the N-terminal amino acids 2-20 of the AR (sc-816, lot number E1004; Santa Cruz Biotechnology). Restraint-responsive neurons were localized using Fos immunoreactivity as a marker of cellular activation using a primary antiserum $(1: 45,000)$ raised against amino acids $4-17$ of the human Fos protein (Ab-5, lot number 4191-1-1; Oncogene Research Products). Immunohistochemistry was performed using a conventional nickelintensified, avidin-biotin-immunoperoxidase (Vectastain Elite ABC kit; Vector Laboratories) procedure (Li and Sawchenko, 1998). Before addition of primary antisera, free-floating sections were pretreated with hydrogen peroxide $(0.3 \%)$ to quench endogenous peroxidase activity and with sodium borohydride (1\%) to reduce free aldehydes. Discrete localization of Fos-immunoreactive (IR) profiles to defined regions of the PVN was assisted by redirected sampling of an adjacent series of thionin-stained sections. Total cell number estimates of Fos-IR cells within the PVN, medial amygdala, and the lateral septum were generated by counting bilaterally the number of Fos-positive cells through each region of interest, averaged by dividing the total number of cell counts by slice number, corrected for double counting errors (Guillery, 2002), and multiplying this product by a factor of five to account for slice frequency (1-in-5 sections).

Hybridization histochemistry. An in situ hybridization approach was used to determine relative levels of CRH and AVP mRNA levels in the PVN, amygdala, and bed nucleus of the stria terminalis (BST) under basal conditions, and relative levels of $c$-fos mRNA and CRH and AVP heteronuclear (hn) RNA induced by restraint stress in PVN using $\left[{ }^{33} \mathrm{P}\right] \mathrm{UTP}$-labeled (GE Healthcare) antisense cRNA probes. The CRH mRNA probe was transcribed from a full-length $(1.2 \mathrm{~kb}) \mathrm{cDNA}$ encoding the rat CRH gene. The AVP mRNA probe was transcribed from a $230 \mathrm{bp}$ fragment of the $3^{\prime}$ end of exon $\mathrm{C}$ encoding the rat vasopressin gene. The c-fos mRNA probe was transcribed from a full-length $(2.1 \mathrm{~kb}) \mathrm{cDNA}$ encoding the rat c-fos gene. CRH and AVP gene transcription were detected using cRNA probes transcribed from a $500 \mathrm{bp}$ fragment of the single intron of CRH (Kovács and Sawchenko, 1996) and a 700 bp fragment of intron I of the rat vasopressin gene, respectively (Herman et al., 1991; Cole and Sawchenko, 2002). Techniques for riboprobe synthesis, hybridization, and the patterns of hybridization for these probes have been described in greater detail previously (Simmons et al., 1989; Chan et al., 1993; Viau et al., 2003). Briefly, free-floating sections were first rinsed in KPBS to remove cryoprotectant and then mounted and vacuum dried on glass slides overnight. After postfixation with $10 \%$ formaldehyde for $30 \mathrm{~min}$ at room temperature, sections were digested in proteinase $\mathrm{K}$ (10 $\left.\mathrm{mg} / \mathrm{ml}, 37^{\circ} \mathrm{C}\right)$ for $30 \mathrm{~min}$, acetylated for $10 \mathrm{~min}(2.5 \mathrm{~mm}$ acetic anhydride, $0.1 \mathrm{~m}$ triethanolamine, $\mathrm{pH} 8.0$ ), rapidly dehydrated in ascending ethanol concentrations (50-100\%), and then vacuum dried. Radionucleotide antisense cRNA probes were used at concentrations approximating $2.5 \times 10^{7} \mathrm{cpm} / \mathrm{ml}$ in a solution of $50 \%$ formamide, $0.3 \mathrm{M} \mathrm{NaCl}$, 10 mm Tris, pH 8.0, 1 mm EDTA, 0.05\% tRNA, 10 mm dithiothreitol, $1 \times$ Denhardt's solution, and 10\% dextran sulfate and applied to individual slides. Slides were coverslipped and then incubated overnight at $57.5^{\circ} \mathrm{C}$, after which the coverslips were removed and the sections were washed 
three times in $4 \times$ SSC $(0.15 \mathrm{~m} \mathrm{NaCl}, 15 \mathrm{~mm}$ citric acid, $\mathrm{pH}$ 7.0) at room temperature, treated with ribonuclease A $(20 \mu \mathrm{g} / \mathrm{ml})$ for 30 min at $37^{\circ} \mathrm{C}$, desalted in descending SSC concentrations $(2-0.1 \times$ SSC), washed in $0.1 \times$ SSC for $30 \mathrm{~min}$ at $60^{\circ} \mathrm{C}$, and dehydrated in ascending ethanol concentrations. Based on the strength of the hybridization signal on $\mathrm{x}$-ray film (B-max; GE Healthcare), the hybridized slides were then coated with Kodak NTB2 liquid autoradiographic emulsion and exposed at $4^{\circ} \mathrm{C}$ in the dark with desiccant. Exposure time to emulsion was optimized to ensure that mRNA levels detected were within the linear range of the assay and could be quantified by making relative comparisons in optical density (OD) levels. Slides were developed at $14^{\circ} \mathrm{C}$ with Kodak D-19 for $3.5 \mathrm{~min}$, briefly rinsed in distilled water for $15 \mathrm{~s}$, fixed in Kodak fixer for 6.5 $\mathrm{min}$, and then washed in running water for 45 min at room temperature. Using a standard reference frame, average OD values were determined bilaterally on regularly spaced $(150 \mu \mathrm{m})$ intervals through each nucleus of interest and corrected by background subtraction. Hybridized tissue series were aligned using white matter morphology illuminated under dark-field conditions and the cytoarchitectonic features provided by an adjacent series of thionin-stained material.

Parceling of the rat brain, as defined by the morphological features provided by thionin staining, was based on the terminology of Swanson (2004) and Swanson and Kuypers (1980) to describe the PVN, Dong and Swanson (2004) to describe the anterior and posterior divisions of the bed nucleus of the stria terminalis, and Swanson and colleagues (Canteras et al., 1995; Dong et al., 2001a) to describe the central and medial amygdala. Features and terminology to describe the MPN were based on those of Simerly and Swanson (Simerly et al., 1986; Simerly and Swanson, 1986, 1988). Discrete localization of transcripts and Fos-IR profiles within the PVN was defined by redirected sampling of Nissl staining patterns aligned to adjacent corresponding dark-field and bright-field images, respectively. Once having identified the posterior magnocellular, and periventricular, dorsal and lateral parvicellular parts, the entire dorsal body of the remaining medial parvocellular (mpd) part of the nucleus was used for quantitative purposes, as described previously (Viau and Sawchenko, 2002). Light- and dark-level images were captured using a Retiga 1300 CCD digital camera (Q-imaging), analyzed using Macintosh OS X-driven, Open Lab Image Improvision version 3.0.9 (Quorum Technologies), and NIH Image J version 1.38 software, and then exported to Adobe Photoshop version 10.0 (Adobe Systems), in which standard methods were used to adjust contrast and brightness for final assembly and labeling.

Statistics. Immunohistochemical and in situ hybridization and hormone comparisons were made observer-blind by assigning coded designations to the data and tissue sets in advance. Grouped data from the immunoperoxidase and hybridization histochemical analyses were compared using a two-way (between treatment, within subject) mixed-design ANOVA using side as the repeated measure. When main effects and interactions between treatment and side were found to be significant $(p<0.05)$, additional comparisons were made using Newman-Keuls post hoc tests to assess significance of side within treatments. Data were analyzed using absolute measures in all cases (Aabel version 3.0.4; Gigawiz). To underscore effects lateralized to the sides of the nuclei ipsilateral to the MPN implants, Fos- and neuropeptide-based expression data are illustrated as the mean \pm SEM percentage of the contralateral (non-implanted) side.

\section{Results}

Implant placements and control studies

Animals receiving unilateral control implants (beeswax only) were initially compared with surgical shams to determine
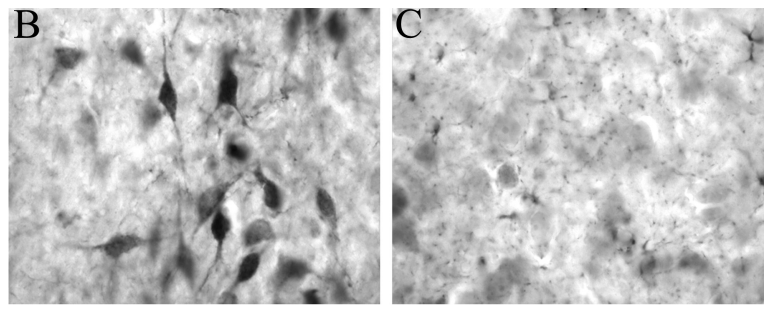

oc
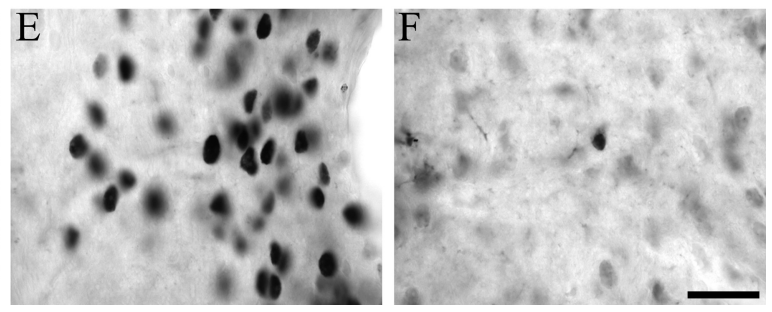

Figure 1. Representative bright-field photomicrographs to show the unilateral induction of AR staining after implants of hydroxylutamide $(\boldsymbol{A}-\boldsymbol{C})$ and testosterone $(\boldsymbol{D}-\boldsymbol{F})$ in castrated male rats. Low magnification shows that $A R$ is restricted to side show that $A R$ is diffusely located within the cytoplasm in response to hydroxyflutamide $(\boldsymbol{B})$, whereas testosterone 列 $25 \mu \mathrm{m} ; \boldsymbol{A}, \boldsymbol{D}, 500 \mu \mathrm{m}$.

whether physically disrupting the MPN could induce downstream effects on the PVN, BST, and amygdala. For all of these regions, relative levels of stress-induced Fos and CRH and AVP mRNA expression were comparable between control and sham animals. Furthermore, no lateralized effects were found for these transcripts within control animals. Based on these results, the effects of steroid/antagonist implants within experimental animals were compared against control animals bearing beeswax implants only.

The caudal part of the MPN is conspicuously composed of magnocellular neurons and shows a high density of AR staining that almost completely mirrors its contours. In castrated male rats bearing androgen implants in the MPN, the radius of diffusion was spherical in nature and fairly consistent between animals, never exceeding $>400 \mu \mathrm{m}$ from the edge of the wax implant. Along its rostrocaudal axis, the highest number of ARpositive cells in the MPN that project to the PVN are biased toward the caudal part of the nucleus (Williamson and Viau, 2007). Castrated rats bearing proper implants within the intended caudal level of the MPN showed induction of AR staining in the MPN proper and surround, including parts of the medial preoptic area (Fig. 1). Rostrally, the induction of AR extended throughout the medial parts of the nucleus but not within the anterior part of the MPN or the anterior division of the BST. At the level of the implant, AR staining was detected in the preoptic periventricular nucleus located immediately adjacent to the MPN, but not within other periventricular structures, nor the anterior part of the anterior hypothalamic nucleus. At the most caudal extent of the MPN, at the level of the posterior division of the BST, AR immunoreactivity was occasionally induced within the medial ventral part of the interfascicular nucleus but never as far as its dorsal and lateral parts. Importantly, AR induction did not occur within the transverse and principal nuclei of the posterior BST (Fig. 2), regions normally containing high concentrations of $\mathrm{AR}$ and providing an inhibitory influence on HPA effector neurons of the PVN (Choi et al., 2007). Experimental animals showing implants that missed the intended caudal part of the MPN induced levels of AR immunoreactivity to suggest ven- 


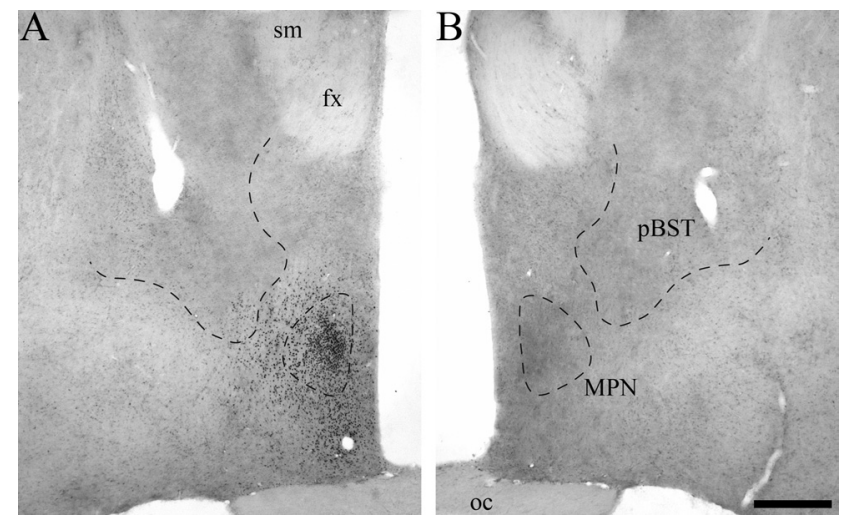

Figure 2. Histological assessment of androgen receptor staining to approximate the diffusion characteristics of testosterone from wax implants directed at the MPN in castrated male rats. After unilateral implants of testosterone in the MPN, AR immunoreactivity was confined to an annulus surrounding the wax implant on ipsilateral $(\boldsymbol{A})$ but not on the contralateral side $(\boldsymbol{B})$. $\mathrm{fx}$, Fornix; oc, optic chiasm; pBST, bed nucleus of the stria terminalis, posterior part; sm, stria medullaris. Scale bar, $400 \mu \mathrm{m}$.

tricular contamination or were not sufficiently removed from other putative regulators of the HPA axis were removed from subsequent analysis. Based on these exclusion criteria, a final $n$ values of 6-7 was achieved for each of the treatment groups under basal and stress conditions.

Additional comparisons on the ability of MPN implants to induce local effects in the posterior BST were performed by quantifying relative levels of AVP mRNA and numbers of AR-IR cells between animals bearing MPN and control implants. There were no significant effects for treatment and side and no significant treatment by side interactions for either of these variables $(p>$ 0.5 in all cases). Because AR immunoreactivity and AVP mRNA levels within the region of the posterior BST are extremely sensitive to androgens (van Leeuwen et al., 1985; De Vries and Panzica, 2006), these findings provide some indication that the region of the posterior BST was effectively avoided in the experimental animals chosen for analysis.

Testosterone and corticosterone can interact on the process of glucocorticoid-mediated negative feedback regulation of the HPA axis within several brain regions (Viau et al., 1999, 2001), including those investigated in the current study. There was no overall effect of treatment $(p=0.74)$ on the concentration of testosterone in plasma: hydroxyflutamide, $2.36 \pm 0.31 \mathrm{ng} / \mathrm{ml}$; testosterone, $2.00 \pm 0.57 \mathrm{ng} / \mathrm{ml}$; and control, $1.83 \pm 0.50 \mathrm{ng} / \mathrm{ml}$. Restraint reliably increased ACTH and corticosterone secretion $(p<0.0001)$, but there were no significant effects of treatment $(p \geq 0.065)$ and no significant interactions between treatment and time $(p \geq 0.08)$. Together, no significant differences were found for testosterone secretion and HPA outflow as a function of MPN implants. This further underscores the utility of using a unilateral implant approach, because it allows us to determine effects related to manipulating AR exposure in the MPN directly, independent of other androgen-sensitive afferent regulators of the HPA axis.

\section{Implant effects on peptide expression in PVN}

Densitometric analysis of relative levels of CRH mRNA in the hypophysiotropic (mpd) zone of the PVN as a function of treatment status under basal conditions revealed no effect of treatment $(p>0.5)$ and no significant interaction between treatment and side $(p=0.32)$ on CRH mRNA (Fig. 3), whose relative strength and distribution was similar across treatment and con- trol groups. Material from the same experiment revealed a significant effect of treatment $(p<0.05)$ and a significant interaction between treatment and side $(p<0.0001)$ on AVP mRNA in the PVN mpd region. The basis for the interaction occurred as a function of lateralized effects within both treatment groups, however, opposite in nature. Thus, relative to the contralateral (non-implanted) side, animals displayed significantly higher and lower levels of AVP mRNA on the side of the PVN ipsilateral to the implants of hydroxyflutamide and testosterone, respectively (Fig. 3).

\section{Implant effects on peptide expression in amygdala and BST}

As we have observed previously, $\mathrm{CRH}$ mRNA in the central amygdala increases in response to elevations of testosterone in circulation but does not rely on a functioning MPN for this effect to occur (Williamson and Viau, 2008). Furthermore, testosterone can act independently of corticosterone to induce CRH expression within the anterior division of the BST (Viau et al., 2001), particularly within the fusiform nucleus. The MPN shows no direct projections to the central amygdala but projects to and/or through multiple regions of the anterior BST capable of relaying limbic information to the PVN, including within the anteromedial, fusiform, and oval nuclei (Herman et al., 1994; Dong et al., 2001b; Dong and Swanson, 2006). The relative levels of $\mathrm{CRH}$ were determined as a function of treatment status under basal conditions to confirm the independence of CRH expression in the amygdala and to test the influence of the implants within the anterior BST. There was no overall effect of treatment $(p>$ 0.5 ) and no significant interaction between treatment and side $(p>0.5)$ on $\mathrm{CRH}$ in the central amygdala, consistent with the lack of input from the MPN to this region of the amygdala (Simerly and Swanson, 1988). Despite the prevalence of MPN projections throughout the anterior division of the BST, there were no significant effects of treatment and side $(p>0.5$ in all cases), and no significant interactions between treatment and side ( $p>0.5$ in all cases) for CRH within anterior BST.

AVP expression in the medial amygdala depends on testosterone in circulation (De Vries et al., 1994). However, the AVP response in the medial amygdala to elevations in plasma testosterone levels is markedly reduced in animals bearing discrete bilateral lesions of the MPN (Williamson and Viau, 2008). Thus, the relative levels of AVP mRNA expression through the rostrocaudal extent of the medial amygdala were determined as a function of treatment status under basal conditions to test an indirect influence of ARs in the MPN. There was no significant effect of treatment $(p=0.06)$ but a significant interaction between treatment and side $(p=0.0009)$. The basis for the interaction occurred as a function of lateralized effects within both treatment groups, however, opposite in nature (Fig. 4). Relative to the contralateral (non-implanted) side, animals displayed significantly higher and lower levels of AVP mRNA on the side of medial amygdala ipsilateral to the implants of testosterone and hydroxyflutamide, respectively.

\section{Implant effects on activational responses to acute restraint stress}

Paraventricular nucleus of the hypothalamus

We initially surveyed the effects of MPN implants on c-fos mRNA levels as a marker of neuronal activation in the PVN under basal conditions and at the termination of $30 \mathrm{~min}$ restraint using the same animals sampled for stress hormones. The $30 \mathrm{~min}$ time point is perhaps too early for detecting significant increments in c-fos mRNA within the lateral septum and medial amygdala (Pace 

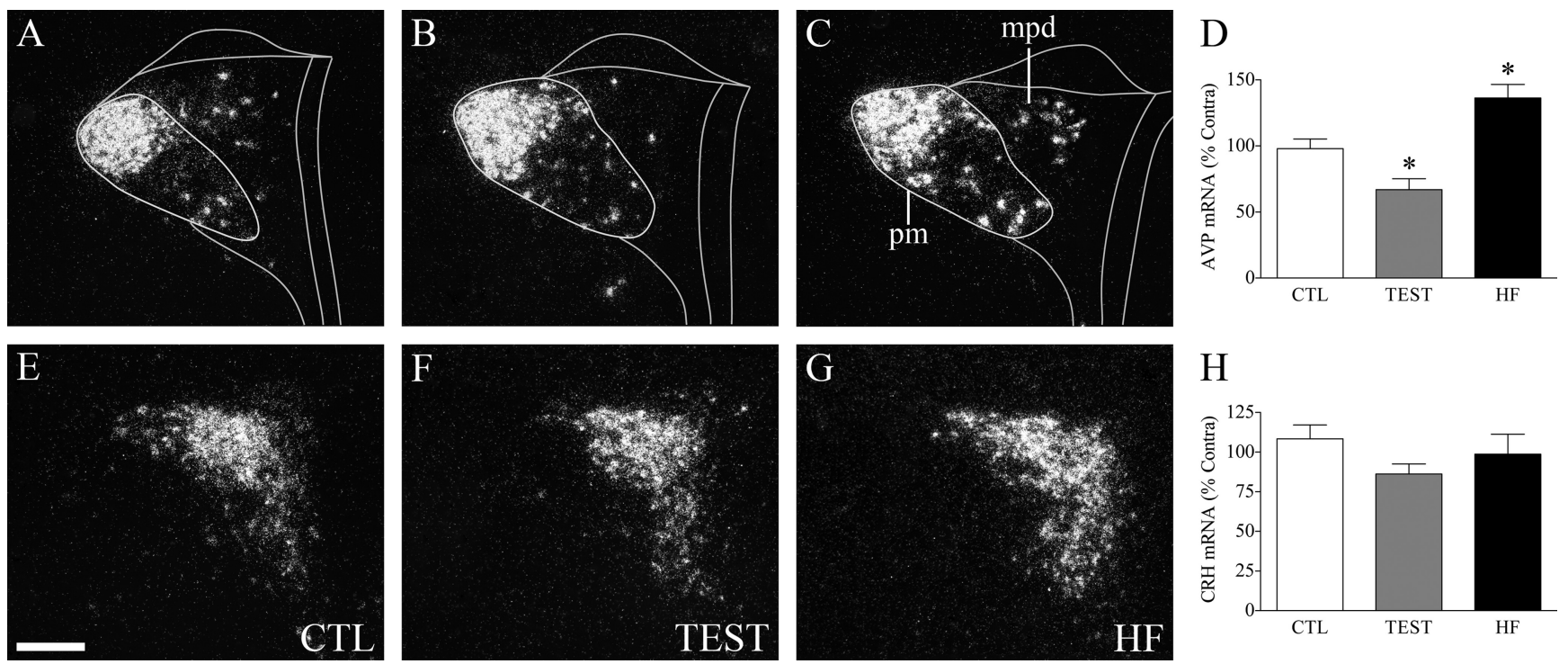

Figure 3. Representative dark-field photomicrographs to show the spatial pattern of AVP $(\boldsymbol{A}-\boldsymbol{C})$ and $C R H(\boldsymbol{E}-\boldsymbol{G})$ mRNA expression in the dorsal body of the mpd part and in the posterior magnocellular (pm) part of the ipsilateral PVN in animals bearing unilateral control (CTL), testosterone (TEST), and hydroxyflutamide (HF) implants in the MPN under basal conditions. Scale bar, 200 $\mu \mathrm{m})$. Mean \pm SEM relative optical density measures (percentage of contralateral values, within treatment) of AVP $(\boldsymbol{D})$ and $C R H(\boldsymbol{H}) \mathrm{mRNA}$ expression within the dorsal body of the mpd in control, testosterone-treated, and hydroxyflutamide-treated animals. ${ }^{*} p<0.05$ versus the contralateral side ( $n=6$ per group).
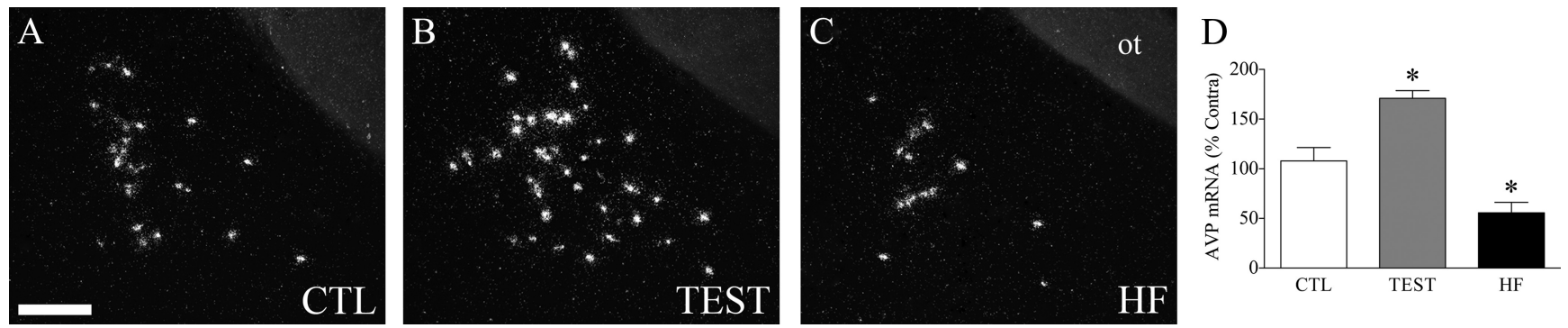

Figure 4. Representative dark-field photomicrographs to show the relative strength of the AVP mRNA $(A-C)$ hybridization signal of the ipsilateral medial amygdala in animals bearing unilateral control (CTL), testosterone (TEST), and hydroxyflutamide (HF) implants in the MPN under basal conditions. ot, Optic tract. Scale bar, $250 \mu \mathrm{m}$ (applies to all). Mean \pm SEM relative optical density measures (percentage of contralateral values, within treatment) of AVP mRNA through the rostrocaudal extent of the medial amygdala in control, testosterone-treated, and hydroxyflutamidetreated animals $(\boldsymbol{D}) .{ }^{*} p<0.05$ versus the contralateral side $(n=6$ per group).

et al., 2005) but represents an interval that is optimal for detecting in this paradigm testosterone- and MPN-dependent changes in c-fos mRNA and protein induction within PVN motor neurons (Viau et al., 2003; Williamson and Viau, 2008), as well as Fos protein labeling within the medial amygdala and lateral septal nuclei (described below).

Rats that did not experience restraint displayed minimal levels of c-fos mRNA in the PVN, but acute restraint caused a marked increased in c-fos mRNA levels within the mpd region (Fig. 5). Comparison of c-fos induction as a function of treatment status revealed no significant effect of treatment $(p=0.20)$, a significant effect of side ( $p=0.0113)$, and a significant interaction between treatment and side $(p=0.0004)$. The basis for these effects occurred as a consequence of lower levels of c-fos mRNA within the testosterone treatment group only, focused on the side of the PVN ipsilateral to the side of the testosterone implant.

Based on the foregoing analyses and our previous findings showing that testosterone and MPN lesions can interact on the number of Fos-IR neurons in PVN, we then extended our survey to the number of cells recruited to express Fos protein within different subregions of the PVN using an adjacent series of tissue from the same animals. Comparisons of Fos cell counts obtained at the termination of $30 \mathrm{~min}$ of restraint revealed no significant effects of treatment and side and no significant interactions between treatment and side within the posterior magnocellular part of the PVN related to posterior pituitary function, nor within the dorsal parvocellular and medial ventral parvocellular autonomic-related parts ( $p \geq 0.34$ in all cases). For the mpd region, there was no significant effect of treatment $(p=0.06)$, a significant effect of side $(p=0.0038)$, and a significant interaction between treatment and side $(p=0.0074)$. Identical to the effects seen for c-fos mRNA induction, the interaction was once again based within the testosterone treatment group only, in which animals showed a lower number of mpd cells recruited to express Fos protein on the side of the PVN ipsilateral to the testosterone implant (Fig. 5).

Stress- and neurotransmitter-induced activation of parvocellular neurons are accompanied by marked increases in CRH and AVP transcription, which are alleged to initiate the replenishment of peptide stores consumed by release (Herman et al., 1991, 1992). Furthermore, restraint induced elevations in AVP and $\mathrm{CRH}$ transcription are higher in castrated rats compared with those with testes (Viau et al., 2003), suggesting that testosterone may negatively regulate the transcriptional activation of $\mathrm{CRH}$ and AVP genes within hypophysiotropic neurons. Thus, to determine whether the MPN could contribute to the systemic ef- 

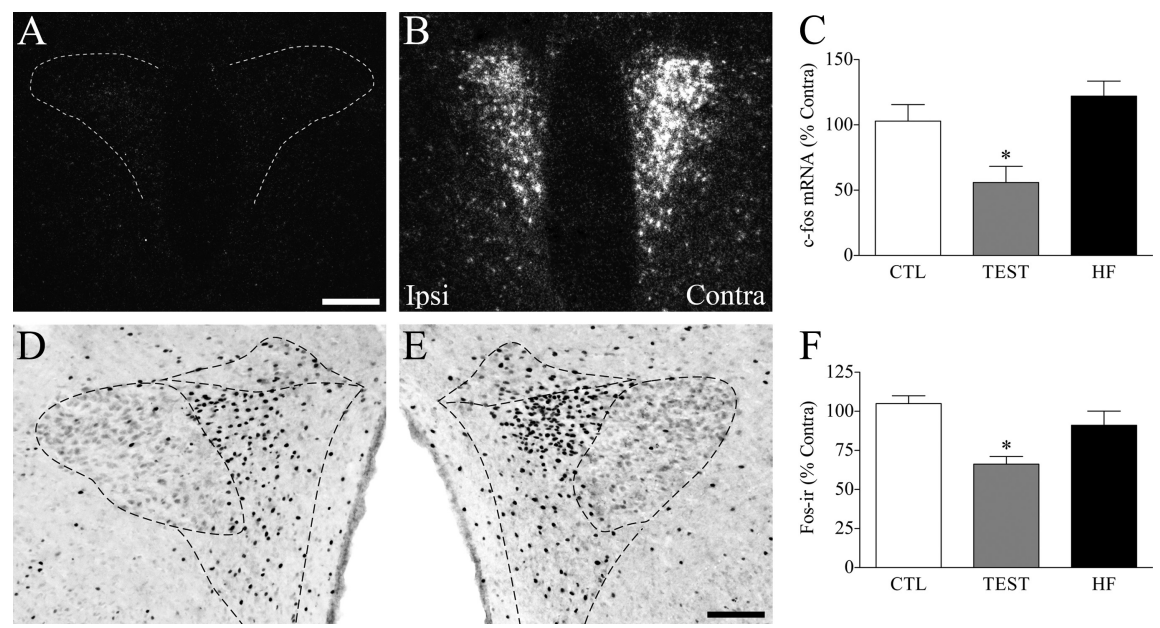

Figure 5. Representative dark-field photomicrographs through the caudal part of the PVN to show c-fos expression under basal conditions $(\boldsymbol{A})$ and at $30 \mathrm{~min}$ of restraint exposure $(\boldsymbol{B})$. Note the dampened expression of c-fos on the side of the PVN ipsilateral to the side of the testosterone implant in the MPN (refer to $\boldsymbol{B}$ ). Scale bar (in $\boldsymbol{A}$ ): $\boldsymbol{A}, \boldsymbol{B}, 150 \mu \mathrm{m}$. Mean \pm SEM relative optical density measures (percentage of contralateral values, within treatment) of c-fos mRNA expression within the medial parvocellular part of the PVN in control (CTL), testosterone (TEST)-treated, and hydroxyflutamide (HF)-treated animals (C). ${ }^{*} p<0.05$ versus the contralateral side ( $n=6$ per group). Bright-field photomicrographs to show Fos-IR staining within medial parvocellular neurons on the sides of the PVN ipsilateral $(\boldsymbol{D})$ and contralateral $(\boldsymbol{E})$ to the side of the testosterone implant at 30 min of restraint exposure. Scale bar (in $\boldsymbol{E}$ ): $\boldsymbol{D}, \boldsymbol{E}, 100 \mu \mathrm{m}$. Note the relative decrement in Fos displayed on the ipsilateral compared with the contralateral side of the nucleus. Mean \pm SEM relative numbers of Fos-IR neurons (percentage of contralateral values, within treatment) within the dorsal body of the mpd in control, testosterone, and hydroxyflutamide implant-treated animals $(\boldsymbol{F}) .{ }^{*} p<0.05$ versus the contralateral side in animals bearing testosterone implants ( $n=6$ per group).

fects of testosterone on gene transcription in the PVN, we examined basal and restraint-induced levels of CRH and AVP hnRNA using a separate cohort of animals bearing MPN implants.

Transcriptional drive of CRH expression under basal conditions was at best represented in only a few dispersed neurons within the mpd region of the PVN. Developed in adjacent series of tissue from the same animals, AVP hnRNA in the mpd region was likewise low, with some expression within presumably ectopic magnocellular neurons. Similar to our previous time course experiments, animals exposed to restraint displayed a significant increase in CRH transcription $(p<0.003)$ at 30 min from the onset of restraint and a significant increase for AVP transcription at 30 and $60 \mathrm{~min}$ from the onset of restraint $(p<0.001$, combined).

Analyses of relative stress-induced levels of CRH hnRNA revealed no significant effects of treatment $(p>0.5)$ and side $(p=$ $0.1926)$ and no significant interaction between treatment and side $(p=0.1923)$. For AVP hnRNA, there was no significant effect of treatment $(p=0.23)$, a significant effect of side ( $p=$ $0.0165)$, and a significant interaction between treatment and side $(p=0.0001)$. The interaction was based within the testosterone treatment group only, in which animals showed lower stressinduced levels of AVP hnRNA on the side of the PVN ipsilateral to the testosterone implant (Fig. 6). Together with the Fos-based data, these findings indicate an inhibitory role for testosterone in the MPN, but no effect of hydroxyflutamide, to regulate synaptic and transcriptional indices of hypophysiotropic activation in the PVN.

\section{Medial amygdala}

The MPN issues significant and primarily unilateral input to the medial amygdala (Chiba and Murata, 1985; Simerly and Swanson, 1988). The dominant site of Fos induction occurred within the posterodorsal part, with fewer cells detected within the pos- teroventral and anteroventral parts of the nucleus. Quantitative assessment of the number of restraint-induced Fos-IR neurons as a function of treatment status through the rostrocaudal extent of the posterodorsal part of the medial amygdala revealed no significant effects of treatment and side ( $p>0.5$ in both cases $)$ and no significant interaction $(p>0.5)$ between treatment and side.

\section{Lateral septal nuclei}

On the bases of functional and connectivity studies, the lateral septum is in a position to relay influences of the MPN on visceromotor responses in the PVN (Simerly and Swanson, 1988; Risold and Swanson, 1997). Determined from the same material used to survey the PVN and medial amygdala under basal and stress conditions, the dominant site of Fos induction in the septal region was localized to the intermediate lateral septal nuclei, with fewer cells detected within the ventral lateral septal nuclei (Fig. 7). Labeling in the medial septal nuclei was quite sparse and for the most part absent in the dorsal lateral and posterior septal nuclei. Quantitative assessment of the number of restraint-induced Fos-IR neurons as a function of treatment status within the lateral septum revealed no significant effect of treatment $(p=0.13)$, a significant effect of side $(p<0.0001)$, and a significant interaction between treatment and side $(p=$ 0.0002). Similar to the PVN, the interaction was based within the testosterone treatment group only, in which animals showed a lower number of cells recruited to express Fos protein on the side of the lateral septum ipsilateral to the testosterone implant (Fig. 7).

\section{Discussion}

Our previous studies have shown that the normal inhibitory effects of testosterone in circulation on stressed-induced PVN activity and HPA outflow are attenuated in animals bearing discrete bilateral lesions of the MPN (Williamson and Viau, 2008). The high containment of androgen receptors within MPN cells identified as projecting to the PVN region directly could form a basis for this functional dependency (Williamson and Viau, 2007). However, the influence of the MPN might also be mediated indirectly through its projections to and/or through various limbic and forebrain structures implicated in the regulation of stressinduced ACTH release. Bilateral manipulations of the MPN can alter testosterone and corticosterone levels in circulation, capable of influencing, therefore, input from other androgen- and glucocorticoid-sensitive brain regions. Thus, in the current study, we adopted a unilateral implant approach to attribute changes in the PVN and its extended circuitries primarily to effects mediated at the level of MPN.

Our current results support an androgen receptor involvement of the MPN to modulate the PVN, while concurrently altering the capacity of neurons to express AVP in the medial amygdala and stress-induced responses within lateral septal nuclei. Because both of these putative regulators of the HPA axis are extensively targeted by the MPN, the present findings underscore 

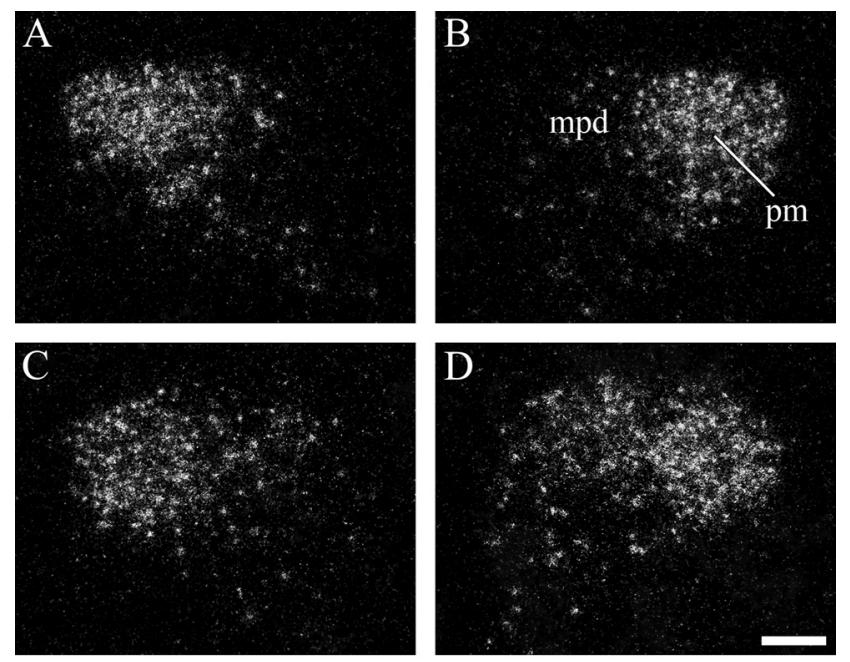

$\mathrm{E}$

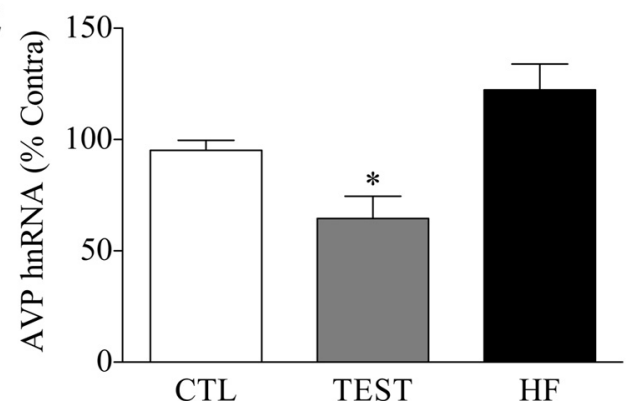

Figure 6. Representative dark-field photomicrographs to show AVP hnRNA expression on the sides of the PVN ipsilateral $(\boldsymbol{A}, \boldsymbol{C})$ and contralateral $(\boldsymbol{B}, \boldsymbol{D})$ to the side of the testosterone implant in the MPN under basal conditions $(\boldsymbol{A}, \boldsymbol{B})$ and at $60 \mathrm{~min}$ of restraint exposure $(\boldsymbol{C}, \boldsymbol{D})$. Scale bar, $100 \mu \mathrm{m}$ (applies to all). Basal levels of expression are significant in the posterior magnocellular (pm) part and scattered throughout the medial parvocellular part of the PVN. Restraint reliably increased the number of hybridized cells in the medial parvocellular part of the PVN, but the relative size and distribution of this response was lower on the ipsilateral $(C)$ compared with the contralateral (D) side of the PVN. Mean \pm SEM relative optical density measures (percentage of contralateral values, within treatment) of AVP hnRNA expression within the dorsal body of the mpd in control (CTL), testosterone (TEST)-treated, and hydroxyflutamide (HF)-treated animals $(\boldsymbol{E}) .{ }^{*} p<0.05$ versus the contralateral side ( $n=7$ per group).

the MPN as an important neural substrate for registering changes in gonadal status and distributing this information to multiple afferent mediators of PVN visceromotor function.

In line with the major unilateral projections of the MPN to the PVN, medial amygdala, and septal nuclei, the basic effects of the implants were lateralized to the sides of the nuclei ipsilateral to the MPN implants. In unstressed animals, testosterone and hydroxyflutamide implants exerted inhibitory and stimulatory influences, respectively, on AVP mRNA within the mpd region of the PVN. These findings remain in line with an upstream influence of testosterone and androgen receptors to regulate the HPA axis above the level of the PVN (Bingham et al., 2006) (but see Lund et al., 2006).

Based on the capacity of testosterone in circulation to operate on both the stress-induced activation and synthesis of AVP neurosecretory neurons, we anticipated similar opposing influences of the implants on the cellular and transcriptional activation of the PVN. In response to restraint, animals bearing unilateral implants of testosterone in the MPN displayed lower levels of c-fos mRNA, smaller numbers of mpd cells recruited to express Fos protein, and lower levels of AVP hnRNA on the sides of the PVN ipsilateral to the testosterone implants. However, there
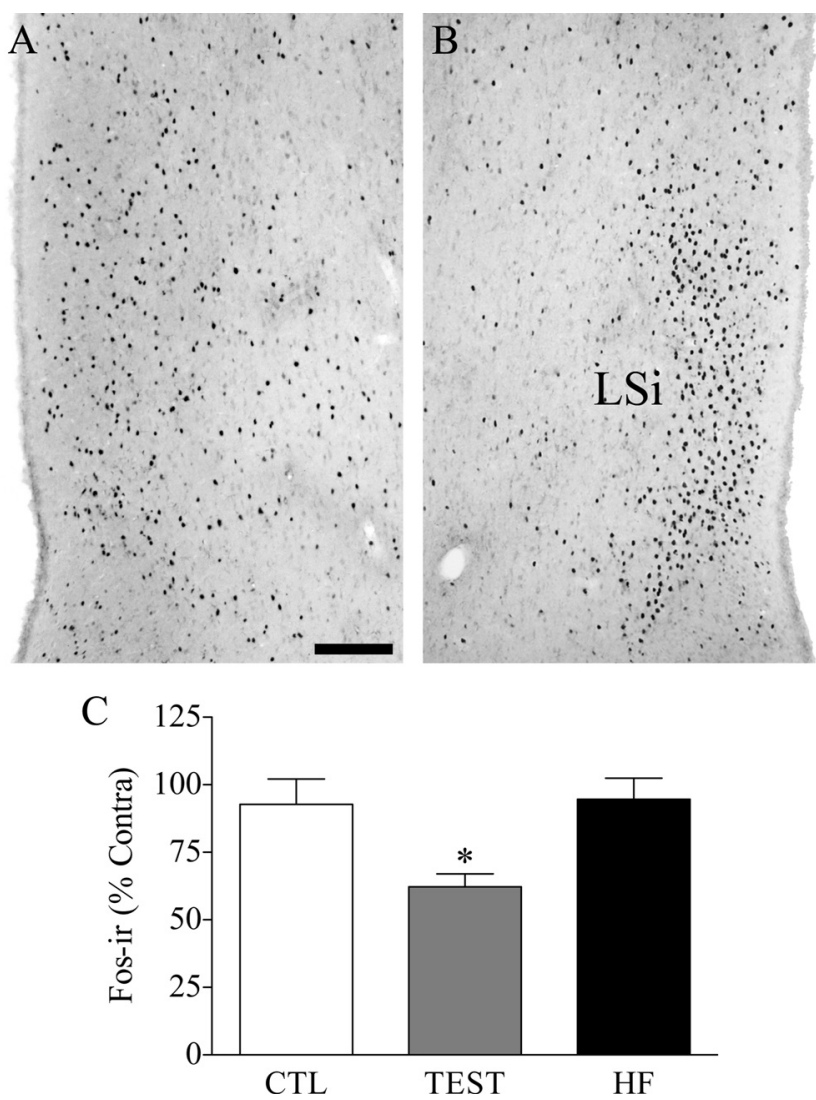

Figure 7. Bright-field photomicrographs to show Fos-IR staining on the sides of the lateral septal nucleus ipsilateral $(\boldsymbol{A})$ and contralateral $(\boldsymbol{B})$ to the side of the testosterone implant in the MPN at 30 min of restraint exposure. LSi, Lateral septum, intermediate part. Scale bar, $150 \mu \mathrm{m}$. Note the relative decrement in Fos displayed on the ipsilateral compared with the contralatera side of the nucleus. Mean \pm SEM relative numbers of Fos-IR neurons (percentage of contralateral values, within treatment) in control (CTL), testosterone (TEST)-treated, and hydroxyflutamide (HF)-treated animals (C). ${ }^{*} p<0.05$ versus the contralateral side in animals bearing implants of testosterone ( $n=6$ per group).

was no such asymmetry for these indices of synaptic and transcriptional activation in the PVN of animals with hydroxyflutamide implants.

In addition to the androgen receptor, cells within the caudal division of the MPN that project most heavily to the PVN contain estrogen receptor- $\alpha$ and $-\beta$ subtypes and the cytochrome P450 enzyme aromatase (Simerly et al., 1990; Shughrue et al., 1997; Zhao et al., 2007). Thus, some of the downstream effects of testosterone may actually be mediated by its local conversion to estrogen and activation of estrogen receptors in the MPN, which could explain why the hydroxyflutamide implants did not fully oppose the effects of testosterone on PVN motor neuron function. This possibility will have to rest until we begin to explore the effects of agents directed at both androgen and estrogen receptors in the MPN.

Alternatively, the extent to which androgen receptors in the MPN are normally recruited to regulate cellular and transcriptional responses to stress may also depend on circulating levels of testosterone. We noted previously that the functional effects of bilateral MPN lesions on stress-induced Fos expression and AVP synthesis in the PVN are discriminated in animals bearing plasma testosterone concentrations in excess of 3-4 ng/ml (Williamson and Viau, 2008), whereas animals in the current study showed plasma testosterone concentrations in the order of $2 \mathrm{ng} / \mathrm{ml}$. Thus, in the absence of higher background levels of testosterone, there 
may have been less of a requirement for the hydroxyflutamide implants to effectively antagonize stress-induced Fos and AVP transcription within the PVN. Because stresses of different types activate different pathways to the HPA axis, we propose that androgen receptors in the MPN may also be recruited in a situation-specific manner, particularly under conditions of repeated stress that promote or require elevations in testosterone secretion (Gomez et al., 2004; Gray et al., 2010).

Lund et al. (2006) have shown that endogenous metabolites of testosterone delivered into the vicinity of the PVN can inhibit the HPA response to immobilization stress and that this occurs locally via the estrogen $\beta$-receptor subtype. As with any one of the cell groups that we have identified previously as expressing androgen receptors and projecting to the PVN, the extent to which any of these are engaged by stress, let alone mechanisms governing local effects of androgens in the PVN, may not be mutually exclusive. Rather, the form and relative contributions for each of these converging influences may ultimately vary with different types of stressors.

Testosterone and hydroxyflutamide implants in the MPN increased and decreased, respectively, AVP mRNA levels in the medial amygdala, the reverse of effects seen in the PVN. Testosterone in circulation stimulates AVP expression in the medial amygdala, and this positive influence is thought to occur directly because the vast majority of these AVP cells stain for androgen receptors (De Vries and Panzica, 2006). However, our findings suggest an overriding and indirect influence of androgen exposure in the MPN to regulate AVP neurons in the medial amygdala. Of note, limbic AVP is not entirely regulated by testosterone, because estradiol synergizes with androgens in circulation to stimulate AVP expression within posterior BST and medial amygdala nuclei (Handa et al., 1987; Wang and De Vries, 1995). Therefore, both androgens and estrogens may likely mediate distal effects in the MPN.

AVP neurons in the medial amygdala target a vast number of brain regions (De Vries and Miller, 1998), including the lateral septum, to effect a broad array of behaviors associated with emotional and coping responses, as well as stress-induced changes in autonomic and HPA activity (Buijs and Van Eden, 2004; Landgraf and Neumann, 2004). Several lines of evidence continue to relate the inhibitory influence of the gonadal axis on HPA function in males to testosterone-dependent increases in extrahypothalamic AVP, including within the medial amygdala. Furthermore, the medial amygdala is critical for the HPA response to stressful stimuli, particularly emotional stressors such as restraint (Dayas et al., 1999). Although the extent to which any of these AVP circuits rely on androgen receptors in the MPN to control the HPA axis remains to be determined, the MPN remains an ideal candidate for harmonizing the central actions of testosterone on behavior and neuroendocrine stress responses.

The lateral septum is a major recipient of multiple limbic efferents and regions of the telencephalon associated with the processing of somatosensory information and projects to numerous HPA-regulating nuclei of the hypothalamus, as well as regions immediately surrounding the PVN (Staiger and Wouterlood, 1990; Risold and Swanson, 1997). Based on this connectivity, perhaps predictably, testosterone implants decreased Fos expression within the lateral septum on the ipsilateral side, strikingly similar to the Fos response in the PVN. We have yet to map patterns of stress-induced Fos within septal nuclei identified as projecting to the PVN region or in receipt of input from the MPN. However, the effects of testosterone appeared preferentially localized to Fos responding neurons within the ventrolateral part of the lateral septum. This area contains a small but reliable number of cells that project to regions immediately surrounding the PVN (Li and Sawchenko, 1998), capable of exerting an inhibitory influence on the PVN and HPA outflow (Roland and Sawchenko, 1993).

An emerging concept is that different repertoires of neuronal populations and signaling molecules are required to meet the demands of different types of stressors (for review, see Joëls and Baram, 2009). The organization of MPN projections implies that this nucleus has the capacity to integrate olfactory, neocortical, somatic, and emotionally relevant information with changes in testosterone in circulation, as well as to coordinate endocrine and autonomic responses to facilitate appropriate adaptive responses. Thus, the MPN represents one of many brain nuclei alleged to orchestrate and fine-tune the response of the brain to diverse challenges. The MPN occupies a unique niche in this regard, because it would appear capable of registering changes in testosterone and distributing information flow to several stress responding systems. In both humans and rodents, the magnitude of the HPA response to stress varies with development, aging, social status, and reproductive experience, and each of these conditions involve dynamic changes in testosterone release (for review, see Williamson et al., 2005). Thus, our findings provide a testable framework for understanding how the MPN accounts for periodic and individual differences in stress responses and predisposition to disease.

\section{References}

Aguilera G (1994) Regulation of pituitary ACTH secretion during chronic stress. Front Neuroendocrinol 15:321-350.

Bingham B, Williamson M, Viau V (2006) Androgen and estrogen receptorbeta distribution within spinal-projecting and neurosecretory neurons in the paraventricular nucleus of the male rat. J Comp Neurol 499:911-923.

Buijs RM, Van Eden CG (2000) The integration of stress by the hypothalamus, amygdala and prefrontal cortex: balance between the autonomic nervous system and the neuroendocrine system. Prog Brain Res 126:117-132.

Canteras NS, Simerly RB, Swanson LW (1995) Organization of projections from the medial nucleus of the amygdala: a PHAL study in the rat. J Comp Neurol 360:213-245.

Chan RK, Brown ER, Ericsson A, Kovács KJ, Sawchenko PE (1993) A comparison of two immediate-early genes, c-fos and NGFI-B, as markers for functional activation in stress-related neuroendocrine circuitry. J Neurosci 13:5126-5138.

Chiba T, Murata Y (1985) Afferent and efferent connections of the medial preoptic area in the rat: a WGA-HRP study. Brain Res Bull 14:261-272.

Choi DC, Furay AR, Evanson NK, Ostrander MM, Ulrich-Lai YM, Herman JP (2007) Bed nucleus of the stria terminalis subregions differentially regulate hypothalamic-pituitary-adrenal axis activity: implications for the integration of limbic inputs. J Neurosci 27:2025-2034.

Christensen LW, Gorski RA (1978) Independent masculinization of neuroendocrine systems by intracerebral implants of testosterone or estradiol in the neonatal female rat. Brain Res 146:325-340.

Cole RL, Sawchenko PE (2002) Neurotransmitter regulation of cellular activation and neuropeptide gene expression in the paraventricular nucleus of the hypothalamus. J Neurosci 22:959-969.

Dayas CV, Buller KM, Day TA (1999) Neuroendocrine responses to an emotional stressor: evidence for involvement of the medial but not the central amygdala. Eur J Neurosci 11:2312-2322.

DeVries GJ, Miller MA (1998) Anatomy and function of extrahypothalamic vasopressin systems in the brain. Prog Brain Res 119:3-20.

De Vries GJ, Panzica GC (2006) Sexual differentiation of central vasopressin and vasotocin systems in vertebrates: different mechanisms, similar endpoints. Neuroscience 138:947-955.

De Vries GJ, al-Shamma HA, Zhou L (1994) The sexually dimorphic vasopressin innervation of the brain as a model for steroid modulation of neuropeptide transmission. Ann N Y Acad Sci 743:95-120.

Dong HW, Swanson LW (2004) Organization of axonal projections from the anterolateral area of the bed nuclei of the stria terminalis. J Comp Neurol 468:277-298. 
Dong HW, Swanson LW (2006) Projections from bed nuclei of the stria terminalis, anteromedial area: cerebral hemisphere integration of neuroendocrine, autonomic, and behavioral aspects of energy balance. J Comp Neurol 494:142-178.

Dong HW, Petrovich GD, Swanson LW (2001a) Topography of projections from amygdala to bed nuclei of the stria terminalis. Brain Res Brain Res Rev 38:192-246.

Dong HW, Petrovich GD, Watts AG, Swanson LW (2001b) Basic organization of projections from the oval and fusiform nuclei of the bed nuclei of the stria terminalis in adult rat brain. J Comp Neurol 436:430-455.

Gomez F, Manalo S, Dallman MF (2004) Androgen-sensitive changes in regulation of restraint-induced adrenocorticotropin secretion between early and late puberty in male rats. Endocrinology 145:59-70.

Gray M, Bingham B, Viau V (2010) A comparison of two repeated restraint stress paradigms on hypothalamic-pituitary-adrenal axis habituation, gonadal status and central neuropeptide expression in adult male rats. J Neuroendocrinol 22:92-101.

Guillery RW (2002) On counting and counting errors. J Comp Neurol 447:1-7.

Handa RJ, Roselli CE, Horton L, Resko JA (1987) The quantitative distribution of cytosolic androgen receptors in microdissected areas of the male rat brain: effects of estrogen treatment. Endocrinology 121:233-240.

Herman JP, Schäfer MK, Watson SJ, Sherman TG (1991) In situ hybridization analysis of arginine vasopressin gene transcription using intronspecific probes. Mol Endocrinol 5:1447-1456.

Herman JP, Schafer MK, Thompson RC, Watson SJ (1992) Rapid regulation of corticotropin-releasing hormone gene transcription in vivo. Mol Endocrinol 6:1061-1069.

Herman JP, Cullinan WE, Watson SJ (1994) Involvement of the bed nucleus of the stria terminalis in tonic regulation of paraventricular hypothalamic CRH and AVP mRNA expression. J Neuroendocrinol 6:433-442.

Joëls M, Baram TZ (2009) The neuro-symphony of stress. Nat Rev Neurosci 10:459-466.

Kovács KJ, Sawchenko PE (1996) Sequence of stress-induced alterations in indices of synaptic and transcriptional activation in parvocellular neurosecretory neurons. J Neurosci 16:262-273.

Kudielka BM, Kirschbaum C (2005) Sex differences in HPA axis responses to stress: a review. Biol Psychol 69:113-132.

Landgraf R, Neumann ID (2004) Vasopressin and oxytocin release within the brain: a dynamic concept of multiple and variable modes of neuropeptide communication. Front Neuroendocrinol 25:150-176.

Li HY, Sawchenko PE (1998) Hypothalamic effector neurons and extended circuitries activated in "neurogenic" stress: a comparison of footshock effects exerted acutely, chronically, and in animals with controlled glucocorticoid levels. J Comp Neurol 393:244-266.

Liebsch G, Wotjak CT, Landgraf R, Engelmann M (1996) Septal vasopressin modulates anxiety-related behaviour in rats. Neurosci Lett 217:101-104.

Lund TD, Hinds LR, Handa RJ (2006) The androgen $5 \alpha$-dihydrotestosterone and its metabolite $5 \alpha$-androstan- $3 \beta, 17 \beta$-diol inhibit the hypothalamo-pituitary-adrenal response to stress by acting through estrogen receptor beta-expressing neurons in the hypothalamus. J Neurosci 26:1448-1456.

Pace TW, Gaylord R, Topczewski F, Girotti M, Rubin B, Spencer RL (2005) Immediate-early gene induction in hippocampus and cortex as a result of novel experience is not directly related to the stressfulness of that experience. Eur J Neurosci 22:1679-1690.

Risold PY, Swanson LW (1997) Connections of the rat lateral septal complex. Brain Res Brain Res Rev 24:115-195.

Roland BL, Sawchenko PE (1993) Local origins of some GABAergic projections to the paraventricular and supraoptic nuclei of the hypothalamus in the rat. J Comp Neurol 332:123-143.

Shughrue PJ, Lane MV, Merchenthaler I (1997) Comparative distribution of estrogen receptor-alpha and -beta mRNA in the rat central nervous system. J Comp Neurol 388:507-525.

Simerly RB, Swanson LW (1986) The organization of neural inputs to the medial preoptic nucleus of the rat. J Comp Neurol 246:312-342.

Simerly RB, Swanson LW (1988) Projections of the medial preoptic nu- cleus: a Phaseolus vulgaris leucoagglutinin anterograde tract-tracing study in the rat. J Comp Neurol 270:209-242.

Simerly RB, Gorski RA, Swanson LW (1986) Neurotransmitter specificity of cells and fibers in the medial preoptic nucleus: an immunohistochemical study in the rat. J Comp Neurol 246:343-363.

Simerly RB, Chang C, Muramatsu M, Swanson LW (1990) Distribution of androgen and estrogen receptor mRNA-containing cells in the rat brain: an in situ hybridization study. J Comp Neurol 294:76-95.

Simmons DM, Arriza J, Swanson LW (1989) A complete protocol for in situ hybridization of messenger RNAs in brain and other tissues with radiolabeled single-stranded RNA probes. J Histotechnol 12:169-181.

Staiger JF, Wouterlood FG (1990) Efferent projections from the lateral septal nucleus to the anterior hypothalamus in the rat: a study combining Phaseolus vulgaris-leucoagglutinin tracing with vasopressin immunocytochemistry. Cell Tissue Res 261:17-23.

Swanson LW (2004) Brain maps: structure of the rat brain, Ed 3. San Diego: Academic.

Swanson LW, Kuypers HG (1980) The paraventricular nucleus of the hypothalamus: cytoarchitectonic subdivisions and organization of projections to the pituitary, dorsal vagal complex, and spinal cord as demonstrated by retrograde fluorescence double-labeling methods. J Comp Neurol 194: 555-570.

Uhart M, Chong RY, Oswald L, Lin PI, Wand GS (2006) Gender differences in hypothalamic-pituitary-adrenal (HPA) axis reactivity. Psychoneuroendocrinology 31:642-652.

van Leeuwen FW, Caffe AR, De Vries GJ (1985) Vasopressin cells in the bed nucleus of the stria terminalis of the rat: sex differences and the influence of androgens. Brain Res 325:391-394.

Viau V, Sawchenko PE (2002) Hypophysiotropic neurons of the paraventricular nucleus respond in spatially, temporally, and phenotypically differentiated manners to acute vs. repeated restraint stress: rapid publication. J Comp Neurol 445:293-307.

Viau V, Chu A, Soriano L, Dallman MF (1999) Independent and overlapping effects of corticosterone and testosterone on corticotropin-releasing hormone and arginine vasopressin mRNA expression in the paraventricular nucleus of the hypothalamus and stress-induced adrenocorticotropic hormone release. J Neurosci 19:6684-6693.

Viau V, Soriano L, Dallman MF (2001) Androgens alter corticotropin releasing hormone and arginine vasopressin mRNA within forebrain sites known to regulate activity in the hypothalamic-pituitary-adrenal axis. J Neuroendocrinol 13:442-452.

Viau V, Lee P, Sampson J, Wu J (2003) A testicular influence on restraintinduced activation of medial parvocellular neurons in the paraventricular nucleus in the male rat. Endocrinology 144:3067-3075.

Viau V, Bingham B, Davis J, Lee P, Wong M (2005) Gender and puberty interact on the stress-induced activation of parvocellular neurosecretory neurons and corticotropin-releasing hormone messenger ribonucleic acid expression in the rat. Endocrinology 146:137-146.

Wang Z, De Vries GJ (1995) Androgen and estrogen effects on vasopressin messenger RNA expression in the medial amygdaloid nucleus in male and female rats. J Neuroendocrinol 7:827-831.

Williamson M, Viau V (2007) Androgen receptor expressing neurons that project to the paraventricular nucleus of the hypothalamus in the male rat. J Comp Neurol 503:717-740.

Williamson M, Viau V (2008) Selective contributions of the medial preoptic nucleus to testosterone-dependant regulation of the paraventricular nucleus of the hypothalamus and the HPA axis. Am J Physiol Regul Integr Comp Physiol 295:R1020-R1030.

Williamson M, Bingham B, Viau V (2005) Central organization of androgen-sensitive pathways to the hypothalamic-pituitary-adrenal axis: implications for individual differences in responses to homeostatic threat and predisposition to disease. Prog Neuropsychopharmacol Biol Psychiatry 29:1239-1248.

Zhao C, Fujinaga R, Tanaka M, Yanai A, Nakahama K, Shinoda K (2007) Region-specific expression and sex-steroidal regulation on aromatase and its mRNA in the male rat brain: immunohistochemical and in situ hybridization analyses. J Comp Neurol 500:557-573. 